\title{
Hard Carbon Derived from Avocado Peels as a High-Capacity, High-Performance Anode Material for
}

\section{Sodium-Ion Batteries}

Francielli Silva Genier ${ }^{1}$, Shreyas Pathreeker ${ }^{1}$, Robson Luis Schuarca ${ }^{1}$, Mohammad Islam ${ }^{2}$, and Ian Dean Hosein $^{1}$

${ }^{1}$ Syracuse University, Syracuse-NY, 13244, USA

${ }^{2}$ State University of New York at Oswego, Oswego-NY, 13126, USA

\section{Abstract}

Deriving battery grade materials from natural sources is a key element to establishing sustainable energy storage technologies. In this work, we present the use of avocado peels as a sustainable source for conversion into hard carbon based anodes for sodium ion batteries. The avocado peels are simply washed and dried then proceeded to a high temperature conversion step. Materials characterization reveals conversion of the avocado peels in high purity, highly porous hard carbon powders. When prepared as anode materials they show to the capability to reversibly store and release sodium ions. The hard carbonbased electrodes exhibit excellent cycling performance, namely, a reversible capacity of $352.55 \mathrm{mAh} / \mathrm{g}$ at $0.05 \mathrm{~A} / \mathrm{g}$, rate capability up to $86 \mathrm{mAh} / \mathrm{g}$ at $3500 \mathrm{~mA} / \mathrm{g}$, capacity retention of $>90 \%$, and $99.9 \%$ coulombic efficiencies after 500 cycles. This study demonstrates avocado derived hard carbon as a sustainable source that can provide excellent electrochemical and battery performance as anodes in sodium ion batteries.

\section{Introduction}

The high demand for lithium-ion batteries has triggered significant research interest in finding alternative ion carriers. Sodium is a great candidate due to its similar physicochemical properties to lithium, high abundance on earth's crust, and lower cost of most active materials. ${ }^{1}$ However, simply transferring lithium battery technologies to sodium conduction is hampered by differences in intercalation mechanisms and 
ionic radius. ${ }^{2,3}$ Notably, graphite, an established anode material of lithium-ion batteries, cannot be simply applied to sodium-ion batteries. The reason is the interlayer distance between the graphene sheets are too small, namely $0.34 \mathrm{~nm}$, for effective $\mathrm{Na}^{+}$insertion. ${ }^{4}$

Suitable alternatives to pure graphite include disordered carbon materials due to its usually higher interlayer distances $(>0.37 \mathrm{~nm})$ and defect-rich structures. ${ }^{4,5}$ Hard carbon, in particular, is especially environmentally and economically advantageous since it is predominately produced by biomass and residues, including fruit peels $^{6-9}$ and nut shells. ${ }^{10-12}$ However, the methodology of obtaining hard carbon could be detrimental to its economic and environmental impact, remarkably due to activation steps and high carbonization temperatures. ${ }^{13}$ The activation method usually consists of soaking the precursor source in an alkaline or acid solution before carbonization with the aim to modify the porosity and surface properties of the hard carbon. ${ }^{6,13,14}$ If transposed to industrial scale, this extra step could translate into additional costs from washing and residue neutralization. Moreover, few reports have shown workable capacities with hard carbon obtained with carbonization temperatures below $1200{ }^{\circ} \mathrm{C},{ }^{13,15}$ and high pyrolyzation temperatures signify a considerable energy demand.

In this work, we aimed to decrease the environmental impact of hard carbon production while also obtaining a suitable active material for sodium-ion intercalation. Hard carbon was produced from avocado peels by carbonization at 900 and $1100{ }^{\circ} \mathrm{C}$ after simply washing the peels with deionized (DI) water. The global demand for avocados has increased exponentially since the 1990s. Each year, an estimation of 5 million tons of avocados are consumed globally. $85 \%$ of the total production corresponds to the Hass variety due to its buttery consistency and thick protective skin - which facilitates trade. ${ }^{16-18}$ In the United States, the avocado market has grown $16 \%$ every year since 2008 and was the $8^{\text {th }}$ most consumed fruit/vegetable in 2019, partially due to potential health advantages and lifestyle trends among millennials and, more recently, Gen $\mathrm{Z}$ individuals. ${ }^{17,19}$ Sold raw or industrially processed, avocados generate waste from their peels, seeds, and even oxidized parts of the pulp. Depending on the species, avocado industrial processing can produce up to $30 \%$ of its weight in solid waste. ${ }^{20,21}$ To reduce the impact of avocado waste, researchers have 
produced activated carbon from avocado peels and seeds for water treatment and dye removal applications. ${ }^{22,23}$ To the best of our knowledge, the potential to produce hard carbon from avocado peels for energy storage has never been explored. The hard carbon produced from avocado peels showed proper graphene interlayer distance, high carbon content, and microporosity that is beneficial to intercalation and electrolyte penetration. As a result, the hard carbon-based electrodes exhibited a great reversible capacity of $352.55 \mathrm{mAh} / \mathrm{g}$ at $0.05 \mathrm{~A} / \mathrm{g}$. Rate capabilities of $86 \mathrm{mAh} / \mathrm{g}$ at $3500 \mathrm{~mA} / \mathrm{g}$ were also achieved, as well as 99.9\% Coulombic efficiencies after 500 cycles.

\section{Materials and Methods}

\section{Material Synthesis}

Avocado peels were collected from the Syracuse University's Food Services and local markets. The excess pulp left in the peels was removed with tap water and then with deionized (D.I.) water at room temperature, with subsequent drying at $115{ }^{\circ} \mathrm{C}$ overnight. The peels were then roughly grounded, washed warm D.I. water at $50{ }^{\circ} \mathrm{C}(500 \mathrm{~mL}$ for $\sim 2.5 \mathrm{~g}$ of dried peels $)$, and dried again at $115^{\circ} \mathrm{C}$ overnight. The resulting solids were put in an alumina crucible and inserted in a Lindberg Blue M tube furnace to be carbonized at 900 or $1100{ }^{\circ} \mathrm{C}$ for 2 hours under Ar flow $(200 \mathrm{sccm})$ with a heating rate of $5 \mathrm{C} / \mathrm{min}$. The resulting hard carbons (labelled herein as HC-900 and HC-1100) were manually grounded using an agate mortar and pestle. From each $1 \mathrm{~g}$ of raw peels, $63.6 \mathrm{mg}$ of hard carbon were obtained. Figure 1 shows a schematic summarizing the hard carbon production towards its final use as an anode component of a battery. 


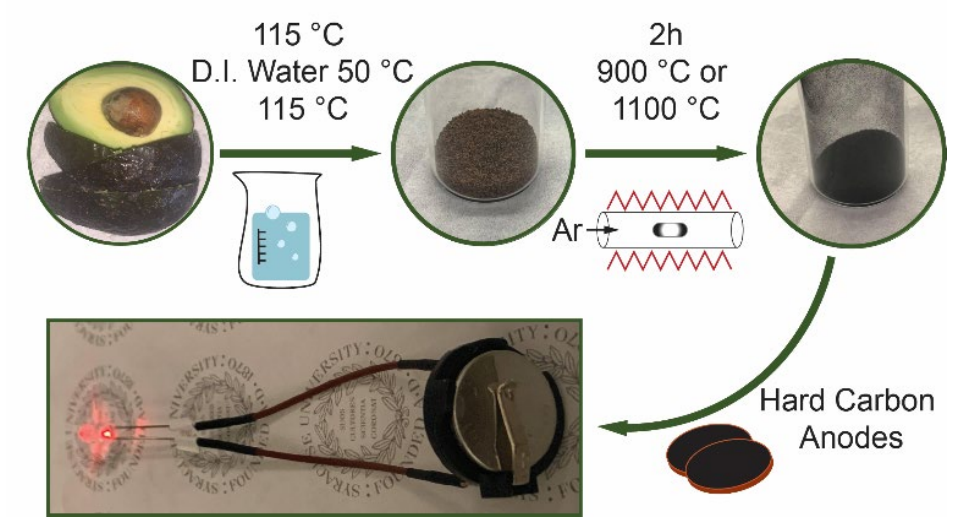

Figure 1. Schematic of the main steps to produce sodium batteries with hard carbon from avocado peels, which successfully operate as an anode in a sodium battery.

\section{Material Characterization}

X-ray diffraction (XRD) measurements were collected on a Rigaku MiniFlex 600 diffractometer with $\mathrm{Cu}$ K $\alpha$ radiation $(\lambda=1.5405 \AA)$. Raman spectroscopy was carried out on a Renishaw inVia confocal microscope using a $532 \mathrm{~nm}$ laser line and a scan time of $10 \mathrm{~s}$ per scan. 10 scans were collected to obtain each spectrum. $\mathrm{N}_{2}(99.999 \%$, Airgas) adsorption isotherm measurements were performed at $77 \mathrm{~K}$ in a surface area and porosity analyzer (Micromeritics ASAP 2020). Total surface areas were determined by Brunauer-Emmett-Teller (BET) and t-plot micropore analyses. Pore volumes were characterized by nitrogen cumulation at a relative pressure of 0.995 . Pore sizes were estimated by Barrett-Joyner-Halenda (BJH) analysis of the desorption branch of $\mathrm{N}_{2}$ uptake isotherms. Scanning electron microscopy was carried out on a JEOL JSM100IT-LA SEM using an accelerating voltage of $10 \mathrm{kV}$. High magnification images and EDS maps were obtained using an accelerating voltage of $20 \mathrm{kV}$.

\section{Electrochemical Characterization}

The electrodes were prepared by mixing the hard carbon, super P (carbon black), and polyvinylidene fluoride (PVDF) at a weight ratio of 8:1:1 in N-Methyl-2-pyrrolidone (NMP) so that $1.5 \mathrm{~mL}$ of solvent was used for $0.5 \mathrm{~g}$ of solid mix. The slurry was sonicated and ball-milled repeatedly until homogeneity, and 
then casted onto copper foil and dried at $80{ }^{\circ} \mathrm{C}$ overnight. The loading mass of active material ranged from 0.86 to $1.02 \mathrm{mg} / \mathrm{cm}^{2}$. Sodium metal and Whatman GF/F microfiber filters were selected as counter electrode and separator, respectively. The electrolyte composition was $0.8 \mathrm{M} \mathrm{NaClO}_{4}$ in ethylene carbonate (EC) and diethyl carbonate (DEC) at a 1:1 (v/v) with $5 \% \mathrm{v} / \mathrm{v}$ fluoroethylene carbonate (FEC) as an additive. The solvent solution was tested regarding water content prior to salt dissolution using a Karl-Fischer (KF) coulometer (Metrohm) titration system. The water concertation was measured to be $\sim 4 \mathrm{ppm}$. CR2032 coin cells were assembled under argon in an MBraun glove box with moisture and oxygen levels below $0.5 \mathrm{ppm}$. Cyclic voltammetry and electrochemical impedance spectroscopy (EIS) measurements were recorded using a Solartron Energy Lab XM Instrument. Galvanostatic charge-discharge tests were performed on an Arbin LBT 8-channel Battery Tester within a potential window of $0.05 \mathrm{mV}-2500 \mathrm{mV}\left(\mathrm{vs} . \mathrm{Na} / \mathrm{Na}^{+}\right.$).

\section{Results and Discussion}

The XRD spectra of hard carbon obtained at both temperatures are presented in Figure 2 (a). The curves show broad peaks around $22^{\circ}$ and $43^{\circ}$, which correspond to the (002) and (100) crystal planes, respectively. The absence of other phases of significant intensity indicate that the mild cleaning procedure with DI water sufficiently removed impurities that would otherwise remain after the sintering step. The difference between washed and unwashed samples can be closely verified, in which uncleaned avocado peels resulted in contaminated hard carbon (Figure S1). As indicated by the arrow in Figure 2 (a), the diffraction peak of the (002) crystal plane shifted slightly to a higher angle, which signifies that the increase in temperature resulted in decreased spacing between the graphite layers, which has been observed by other hard carbon studies. ${ }^{24-26}$ This finding was confirmed by calculating $d_{002}$ with the Bragg formula. HC-900 and HC-1100 showed graphene interlayer distances of 4.07 and $3.95 \AA$, respectively, both greater than the minimum interlayer space of $3.7 \AA \AA$ necessary for $\mathrm{Na}^{+}$insertion in carbon-based materials..$^{25,26}$

Raman spectroscopy was used to further elucidate the disordered nature of the hard carbon, and results are displayed in Figure 2 (b). Both samples showed the two characteristic peaks for carbon-based materials: a D-band peak at approximately $1350 \mathrm{~cm}^{-1}$ that corresponds proportionally to the carbon disorderliness and 
defect presence; and a G-band peak at $\sim 1589 \mathrm{~cm}^{-1}$, a crystalline graphite band. ${ }^{5,27}$ The intensity of each peak informs the material's degree of graphitization. The ratio between the D-band and G-band intensities $\left(I_{D} / I_{G}\right)$ was calculated for HC-900 and HC-1100 and found to be 0.97 and 0.96 , respectively. Such lower $I_{D} / I_{G}$ ratios indicate higher degrees of graphitization, which has been shown to reduce the irreversible capacity in the first cycle. ${ }^{28}$ The slight decrease in defects observed at $1100{ }^{\circ} \mathrm{C}$ is expected as higher temperatures can promote graphitization..$^{25,28,29}$

Figure 2 (c) and (d) show the nitrogen adsorption-desorption isotherms and the estimation of pore size distributions by the Barrett-Joyner-Halenda (BJH) method of the hard carbon samples, respectively. The BET surface area of both samples was $126.03 \mathrm{~m}^{2} / \mathrm{g}$ for HC-900 and $89.79 \mathrm{~m}^{2} / \mathrm{g}$ for HC-1100. This decrease in surface area proportional to the pyrolyzation temperature can be explained by the closuring effect of early stage rising carbonization temperature on micropores. ${ }^{30,31}$ Hard carbons with lower surface areas have demonstrated higher initial Coulomb efficiency (\% ICE) and improved reversible capacities by side reactions and undesirable SEI. ${ }^{5,32}$ The average $\mathrm{BJH}$ pore size estimation was approximately $4.8 \mathrm{~nm}$ for both samples, which has the potential to contribute to sodium ion storage. ${ }^{33}$ 

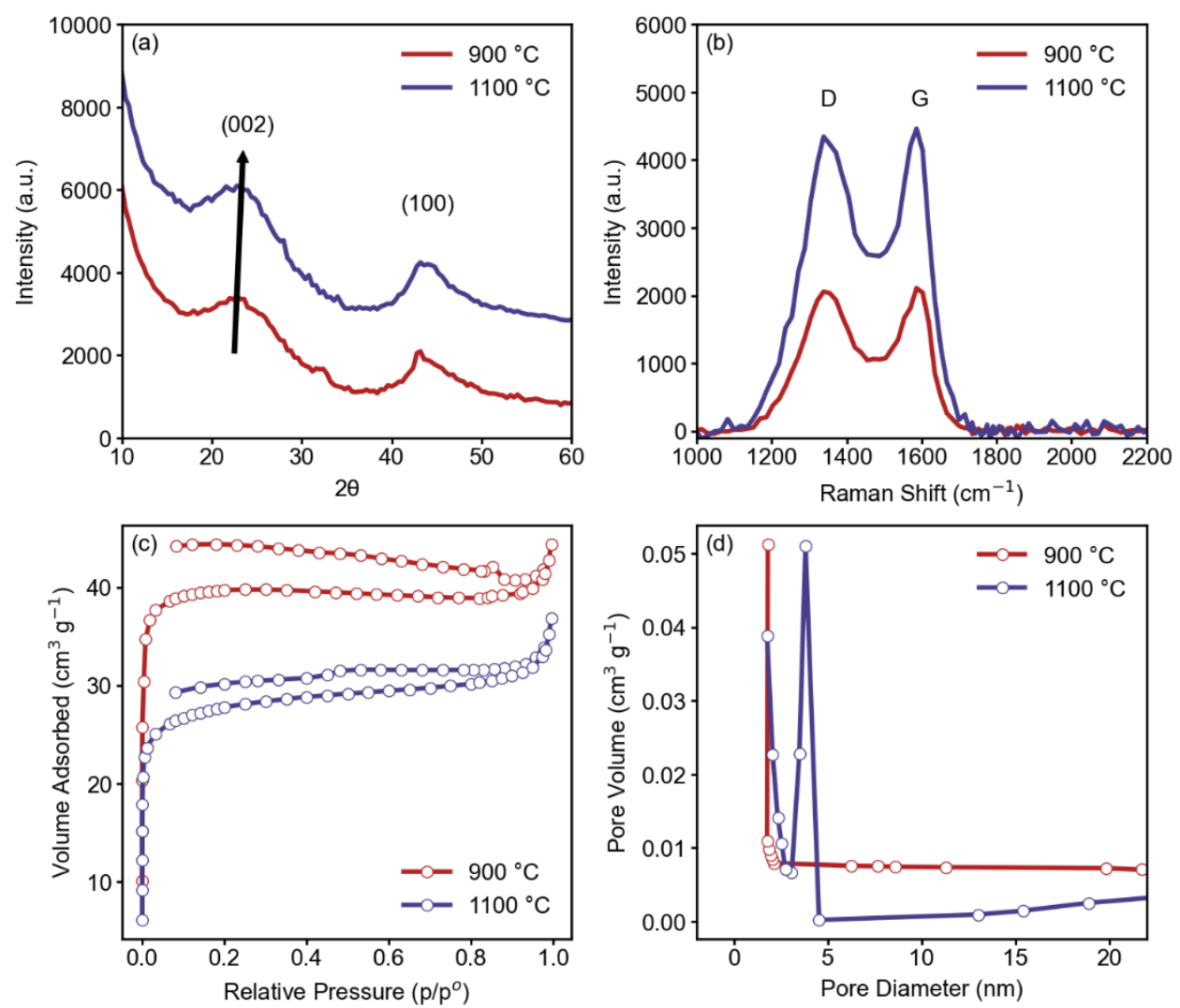

Figure 2. Characterization of avocado peel-derived hard carbon obtained at $900{ }^{\circ} \mathrm{C}(\mathrm{HC}-900)$ and $1100{ }^{\circ} \mathrm{C}(\mathrm{HC}-$ 1100). (a) XRD and (b) Raman spectra. (c) Nitrogen adsorption-desorption isotherms. (d) Estimated pore size distribution.

The morphology of HC-900 and HC-1100 is shown in Figure 3 (a) and (b), including EDX mappings for both samples. As seen in the SEM images, HC-900 has slightly smaller aggregates than HC-1100. This small variation could come from the manual grounding process. EDX mapping of the samples confirms their uniformity and high conversion into hard carbon. Other than carbon, oxygen and potassium are the next two major elements present in the hard carbons, which most likely originates from the organic compounds in avocado peels. Detailed percentages of these elements are displayed in Table 1, alongside other key material characterization data. As shown, the percentage of carbon in HC-1100 is greater than in HC-900, namely, $92.68 \%$ and $84.85 \%$, respectively. The higher purity of HC-1100 was expected due to 
higher conversion temperatures leading to the removal of heteroatoms and complex functional groups. ${ }^{34}$ This result is consistent with the BET surface area, and indicates that HC-1100 could be more suitable for electrode applications.
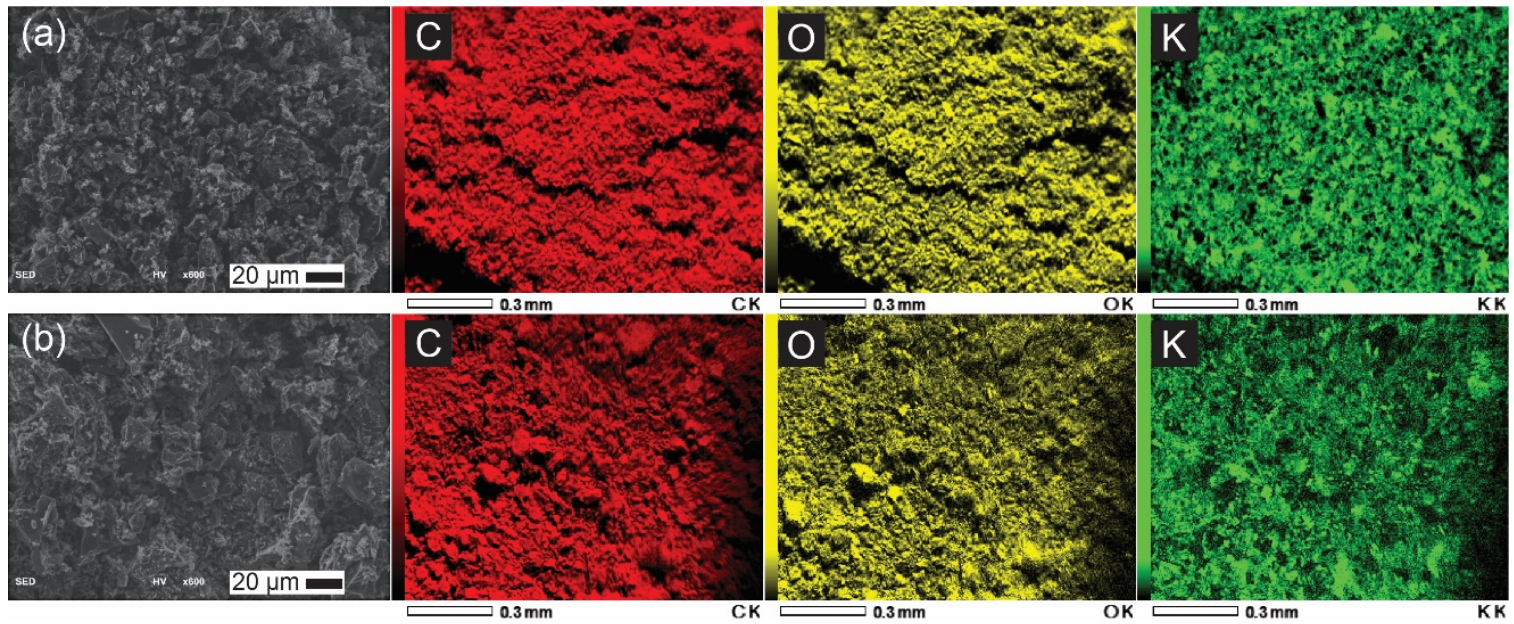

Figure 3. SEM images and EDS mapping of (a) HC-900 and (b) HC-1100. EDS maps of elements with most relevant atomic percentages.

Table 1. Summary of major material characterization results of avocado peel-derived HC-900 and HC1100.

\section{EDS}

XRD Raman BET and BJH Analysis

\section{Atomic Percentages}

$(\%)$

\begin{tabular}{|c|c|c|c|c|c|c|c|c|}
\hline \multirow[t]{2}{*}{ Sample } & \multirow{2}{*}{$d_{002}(\AA)$} & \multirow{2}{*}{$I_{D} / I_{G}$} & \multirow{2}{*}{$\begin{array}{l}\text { Surface Area } \\
\qquad\left(\mathrm{m}^{2} \mathrm{~g}^{-1}\right)\end{array}$} & \multicolumn{2}{|c|}{ Pore Size (nm) } & \multirow{2}{*}{$\mathrm{C}$} & \multirow{2}{*}{$\mathrm{O}$} & \multirow{2}{*}{$\mathrm{K}$} \\
\hline & & & & $d_{a b s}$ & $d_{d e s}$ & & & \\
\hline HC-900 & 4.07 & 0.97 & 126.03 & 5.80 & 3.82 & 84.85 & 14.06 & 0.51 \\
\hline HC-1100 & 3.95 & 0.96 & 89.79 & 4.92 & 4.57 & 92.68 & 6.54 & 0.33 \\
\hline
\end{tabular}


The electrochemical behaviors of HC-900 and HC-1100 anodes were firstly characterized by cyclic voltammetry tests using standard CR2032 coin cells. Figure 4 (a) and (b) show the first three cycles within an electrochemical window of $0.05 \mathrm{mV}$ to $2.5 \mathrm{~V}$ at a sweep rate of $0.25 \mathrm{mV} / \mathrm{s}$. The first discharge curve of both cells shows a small cathodic peak at $\sim 0.5 \mathrm{~V}$ that vanishes on subsequent cycles. This cathodic phenomenon can be attributed to irreversible electrolyte breakdown for form the solid electrolyte interphase (SEI) layer. ${ }^{2,15,35}$ Around $0.01 \mathrm{~V}$, a sharp cathodic peak is observed, which is assigned to $\mathrm{Na}^{+}$intercalation in the graphitic microcrystallites. ${ }^{36}$ The anodic peaks at $\sim 0.2 \mathrm{~V}$ indicate the extraction of sodium ions from the graphite layers. ${ }^{36,37}$ A broad redox region ranging from 0.25 to $1.5 \mathrm{~V}$ corresponds to the adsorption process of $\mathrm{Na}^{+}$on the hard carbon surface. ${ }^{3,36}$ In the HC-900 CV curves, the anodic peaks are almost completely merged to the adsorption slopes, indicating that $\mathrm{Na}^{+}$extraction was less efficient in this sample. This is confirmed by the decrease in intensity of the redox peaks in the subsequent cycles, which corresponds to a reduced concentration of sodium ion in the electrolyte and empty interlayer spaces. This observation can be explained by the lower carbonization temperature leading to higher surface areas and, consequently, increased side reactions. ${ }^{37}$ Inversely, HC-1100 showed excellent insertion-extraction reversibility, suggesting that an $1100{ }^{\circ} \mathrm{C}$ pyrolyzation temperature is high enough to produce suitable hard carbon from avocado peels.

The initial galvanostatic charge-discharge profiles for HC-900 and HC-1100 at $0.05 \mathrm{~A} / \mathrm{g}$ are presented in Figure 4 (c) and (d). The first discharge specific capacities for HC-900 and HC-1100 were, respectively, 269.79 and $500.65 \mathrm{mAh} / \mathrm{g}$, and ICE were $59.10 \%$ and $60.78 \%$. The low ICE, as well as the drop in discharge capacity of the second cycle, can be explained by the irreversible electrolyte decomposition and SEI formation, which is consistent with CV results. Similarly, the first slope observed in the initial discharge profile disappears in the next two discharge curves and can also be assigned to SEI formation. The two subsequent reversible regions are fundamental to the sodium ion storage mechanism. The plateau area is commonly attributed to the absorption of $\mathrm{Na}^{+}$in the hard carbon surface and porosity, while the platform region corresponds to the intercalation process of $\mathrm{Na}^{+} \cdot{ }^{14,36}$ As clearly seen, $\mathrm{HC}-1100$ delivered a higher 
capacity and ICE than HC-900, as expected from the BET results. The results in Figure 4 (c) and (d) also indicate a reversible capacity of 150.06 and $352.55 \mathrm{mAh} / \mathrm{g}$ for HC-900 and HC-1100, respectively, both with Coulombic efficiency above $96 \%$. Due to the higher reversible capacity and better overall characteristics, further cycling studies were conducted only with hard carbon obtained at $1100{ }^{\circ} \mathrm{C}$ (HC1100).
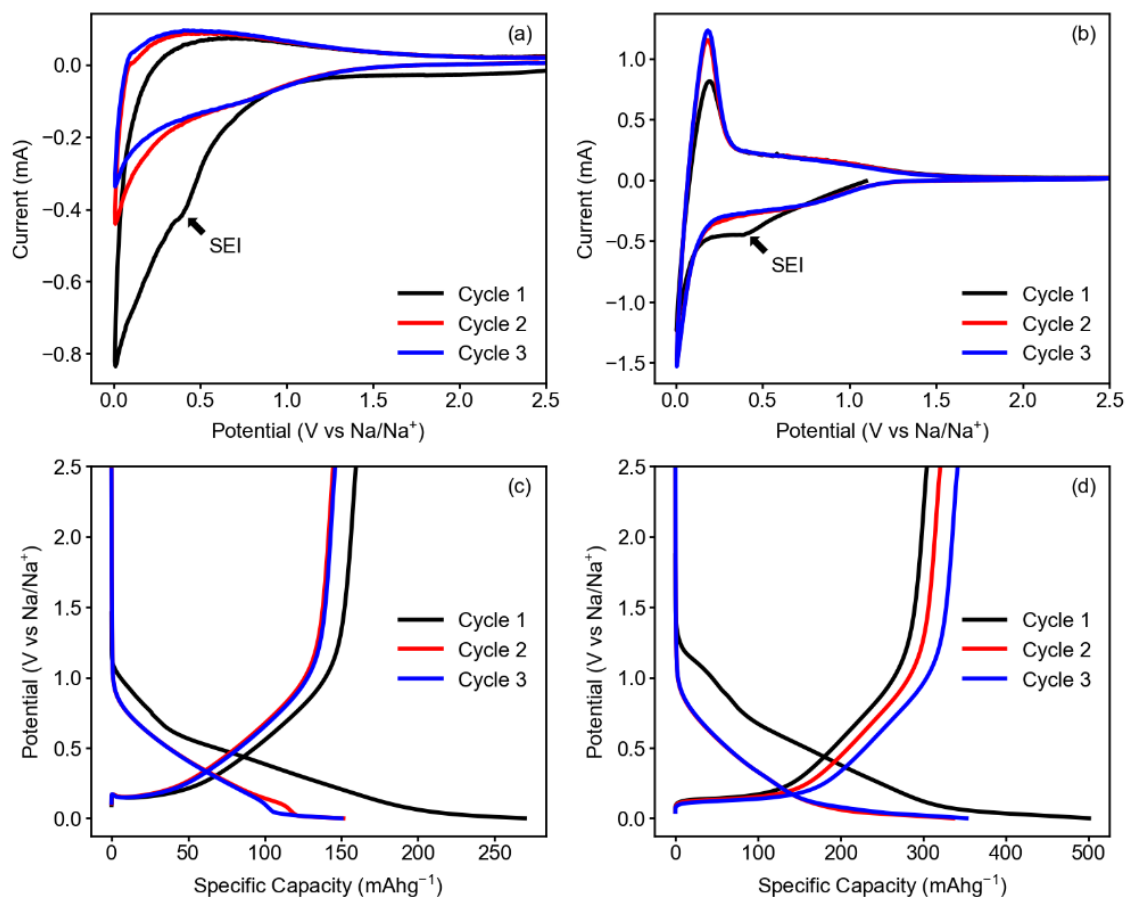

Figure 4. Electrochemical measurements of avocado-peel derived hard carbon anodes. Cyclic voltammetry at 0.25 $\mathrm{mV} \mathrm{s}^{-1}$ of coin cells with sodium metal cathode, and $0.8 \mathrm{M} \mathrm{NaClO} 4$ in DEC:EC+FEC (1:1+5\% vol.), and hard carbon anode produced from (a) HC-900 and (c) HC-1100. Galvanostatic charge/discharge profiles of half-cells with same configuration and hard carbon anodes from (b) HC-900 and (d) HC-1100. The first three cyclic voltammetry and galvanostatic cycles are displayed.

Figure 5 shows the cycling performance of the hard carbon electrode. The first 50 cycles obtained at a 0.05 $\mathrm{A} / \mathrm{g}$ rate are presented in Figure 5 (a). The expected capacity drop from the first to the second cycle was followed by a considerable increasing trend until cycle 5, increasing from 336.18 to $370.22 \mathrm{mAh} / \mathrm{g}$. This result implies an activation process that occurs during the first cycles and could be related to an interlayer 
rearrangement that provided new $\mathrm{Na}^{+}$storage sites. ${ }^{38}$ Alternatively, this initial increase in rate capacity could also be caused by a slower wetting process of the electrode with electrolyte. ${ }^{39}$ Overall, the cells showed a stable discharge capacity of $\sim 320 \mathrm{mAh} / \mathrm{g}$, with capacity retention of $93.63 \%$ (with respect to the $2^{\text {nd }}$ cycle) and Coulombic efficiency of $99.60 \%$ after all 50 cycles. Figure 5 (b) shows the $2^{\text {nd }}, 35^{\text {th }}$, and $50^{\text {th }}$ cycling profiles from the same galvanostatic study shown in Figure 5 (a). As can be clearly seen, the discharge curves almost completely overlap, further confirming the high reversibility of $\mathrm{Na}^{+}$intercalation in our avocado-derived hard carbon. The rate performance was evaluated at different current densities (Figure $5(\mathrm{c})$ ). During the entire experiment, the CE remained above $94 \%$ with a final value of $98.12 \%$. From the initial discharge capacity at $0.05 \mathrm{~A} / \mathrm{g}$ to the last capacity at a $3.5 \mathrm{~A} / \mathrm{g}$ rate, the retention was $26.02 \%$. The stable capacity at such a high rate indicates optimal conductivity of the studied hard carbon. ${ }^{29}$ To further investigate the cyclic stability at $3.5 \mathrm{~A} / \mathrm{g}$, a cell was cycled 500 times at this rate, and cycling results are presented in Figure 5 (d). The capacity was stable at $\sim 86 \mathrm{mAh} / \mathrm{g}$, with a $99.91 \% \mathrm{CE}$ was maintained after 500 cycles. The steady increase of capacity after the first drops was also observed, indicating the presence of a similar activation process at higher current densities. This observation coupled with the low ICE of $29.44 \%$ indicates that further improvements to prevent irreversible capacities can benefit initial cycling at higher rates. In that sense, EIS impedance measurements were collected after the first cycle and after 50 cycles at $1 \mathrm{~A} / \mathrm{g}$ (Figure S2). From the impedance fittings, the SEI resistance (REI) decreased from 181.08 to $82.10 \Omega$ after cycling, indicating that the SEI films successfully stabilized the electrodes and contributed to longer cycling stabilities. ${ }^{40}$ 

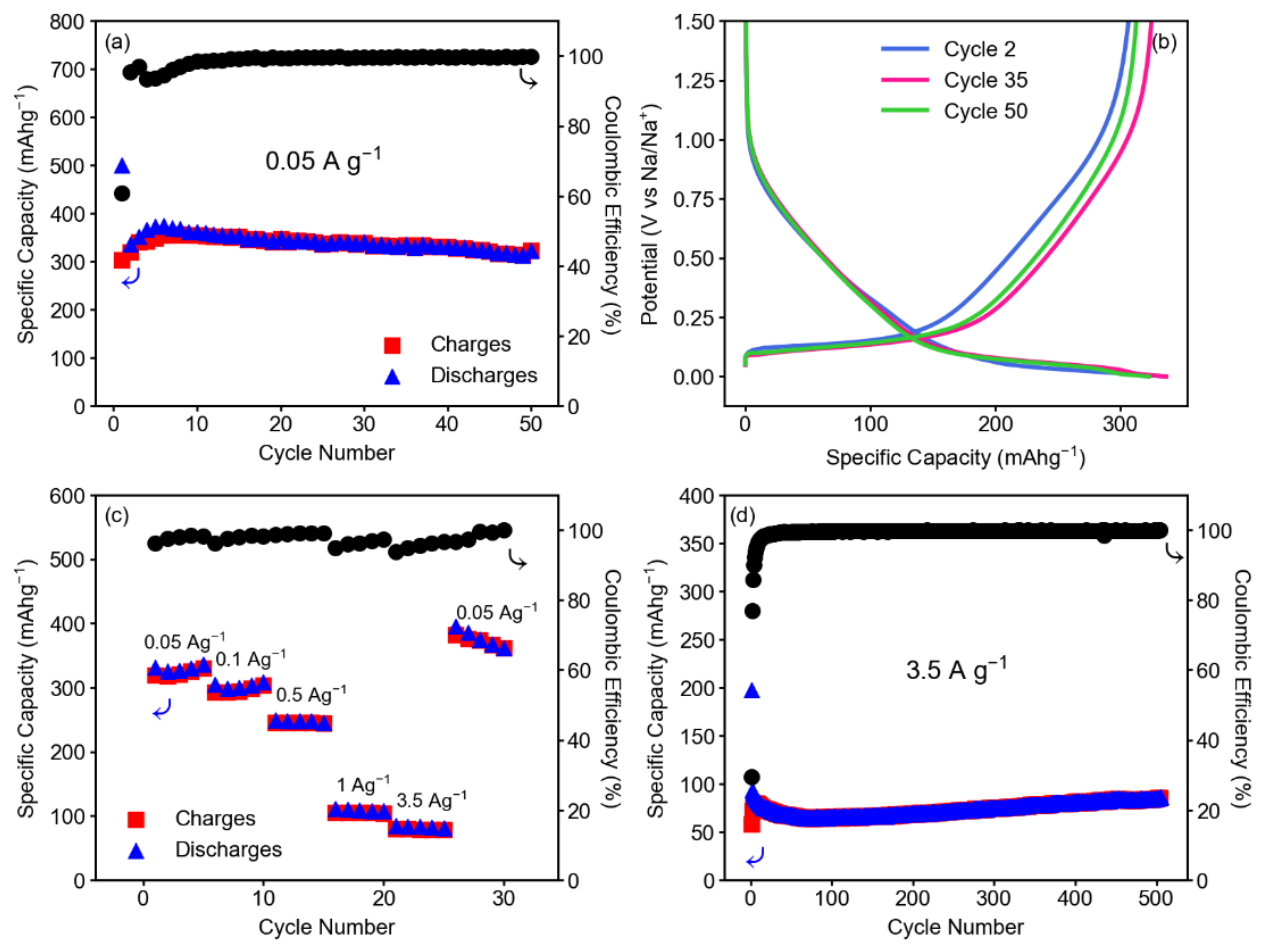

Figure 5. Battery cycling studies. (a) Galvanostatic charge/discharge capacities and coulombic efficiencies of CR2032 cells with a sodium metal cathode, and $0.8 \mathrm{M} \mathrm{NaClO} 4$ in DEC:EC+FEC (1:1+5\% vol.) as electrolyte, and hard carbon anode produced from HC-1100. The measurements were collected using a current rate of $0.05 \mathrm{~A} \mathrm{~g}^{-1}$. (b) Galvanostatic profiles of $1^{\text {st }}, 21^{\text {st }}$ and $36^{\text {th }}$ cycles of same sodium half-cell as in item (a). (c) Rate performance and coulombic efficiencies of sodium half-cell under different current rates. (d) Galvanostatic charge/discharge capacities and coulombic efficiencies collected at $3.5 \mathrm{~A} \mathrm{~g} \mathrm{~g}^{-1}$.

When compared with reported hard carbons that did not undergo any acidic or alkaline activation, nor any doping, the untreated hard carbon presented in this work demonstrated superior reversible capacities and rate performance. Beda et.al. evaluated the effect of natural impurities in biomass-derived hard carbon as anode materials. ${ }^{24}$ The maximum capacity achieved was $214 \mathrm{mAh} / \mathrm{g}$ at a rate of $37.2 \mathrm{~mA} / \mathrm{g}$ for untreated hard carbon carbonized at $1300{ }^{\circ} \mathrm{C}$. Similarly, Alvin et. al. reported reversible capacity of $231 \mathrm{mAh} / \mathrm{g}$ at a $50 \mathrm{~mA} / \mathrm{g}$ rate from commercial microcrystalline cellulose powder carbonized at $1300{ }^{\circ} \mathrm{C},{ }^{41}$ which demonstrates that our method leaded to better performance with less energetic cost. 


\section{Conclusion}

In summary, we produced high performance hard carbon from avocado peels via a simple and inexpensive route. No pretreatment, activation, or chemical washing methods were necessary to produce hard carbon at $1100{ }^{\circ} \mathrm{C}$ with 92.68 at $\%$ of carbon, suitable mesoporosity, and interlayer spacing above the necessary for sodium intercalation (> $3.7 \AA$ ). Electrochemical measurements confirmed the applicability of avocadoderived hard carbon as electrode active materials, with high reversible capacities of $320 \mathrm{mAh} / \mathrm{g}$ over 50 cycles at $50 \mathrm{~mA} / \mathrm{g}$, good rate performance of $86 \mathrm{mAh} / \mathrm{g}$ at $3500 \mathrm{~mA} / \mathrm{g}$, and Coulombic efficiencies above $99.9 \%$ after 500 cycles. This work offers a facile, greener, and low-cost route to produce hard carbon from avocado peels, an abundant source that yields a promising anode material for high rate performance sodiumion batteries.

\section{Acknowledgements}

The authors gratefully acknowledge funding supported by the National Science Foundation under grant number CMMI-1751621, the 3M foundation (Non-tenured Faculty Award), as well as support from the College of Engineering and Computer Science at Syracuse University. F.S.G. is grateful to Syracuse University for Graduate Fellowship support.

\section{References}

(1) Yabuuchi, N.; Kubota, K.; Dahbi, M.; Komaba, S. Research Development on Sodium-Ion Batteries. Chem. Rev. 2014, 114 (23), 11636-11682. https://doi.org/10.1021/cr500192f.

(2) Slater, M. D.; Kim, D.; Lee, E.; Johnson, C. S. Sodium-Ion Batteries. Adv. Funct. Mater. 2013, 23 (8), 947-958. https://doi.org/10.1002/adfm.201200691.

(3) Jin, Q.; Wang, K.; Feng, P.; Zhang, Z.; Cheng, S.; Jiang, K. Surface-Dominated Storage of Heteroatoms-Doping Hard Carbon for Sodium-Ion Batteries. Energy Storage Mater. 2020, 27 (September 2019), 43-50. https://doi.org/10.1016/j.ensm.2020.01.014. 
(4) Tsai, P. C.; Chung, S. C.; Lin, S. K.; Yamada, A. Ab Initio Study of Sodium Intercalation into

Disordered Carbon. J. Mater. Chem. A 2015, 3 (18), 9763-9768. https://doi.org/10.1039/c5ta01443c.

(5) Zhu, Z.; Liang, F.; Zhou, Z.; Zeng, X.; Wang, D.; Dong, P.; Zhao, J.; Sun, S.; Zhang, Y.; Li, X. Expanded Biomass-Derived Hard Carbon with Ultra-Stable Performance in Sodium-Ion Batteries. J. Mater. Chem. A 2018, 6 (4), 1513-1522. https://doi.org/10.1039/c7ta07951f.

(6) Ghosh, S.; Santhosh, R.; Jeniffer, S.; Raghavan, V.; Jacob, G.; Nanaji, K.; Kollu, P.; Jeong, S. K.; Grace, A. N. Natural Biomass Derived Hard Carbon and Activated Carbons as Electrochemical Supercapacitor Electrodes. Sci. Rep. 2019, 9 (1), 1-15. https://doi.org/10.1038/s41598-019-52006$\mathrm{x}$.

(7) Saha, A.; Sharabani, T.; Evenstein, E.; Nessim, G. D.; Noked, M.; Sharma, R. Probing Electrochemical Behaviour of Lignocellulosic, Orange Peel Derived Hard Carbon as Anode for Sodium Ion Battery. J. Electrochem. Soc. 2020, 167 (9), 090505. https://doi.org/10.1149/19457111/ab7c55.

(8) Baldinelli, A.; Dou, X.; Buchholz, D.; Marinaro, M.; Passerini, S.; Barelli, L. Addressing the Energy Sustainability of Biowaste-Derived Hard Carbon Materials for Battery Electrodes. Green Chem. 2018, 20 (7), 1527-1537. https://doi.org/10.1039/c8gc00085a.

(9) Arie, A. A.; Kristianto, H.; Demir, E.; Cakan, R. D. Activated Porous Carbons Derived from the Indonesian Snake Fruit Peel as Anode Materials for Sodium Ion Batteries. Mater. Chem. Phys. 2018, 217, 254-261. https://doi.org/10.1016/j.matchemphys.2018.06.076.

(10) Kumar, U.; Wu, J.; Sharma, N.; Sahajwalla, V. Biomass Derived High Areal and Specific Capacity Hard Carbon Anodes for Sodium-Ion Batteries. Energy and Fuels 2021, 35 (2), 1820-1830. https://doi.org/10.1021/acs.energyfuels.0c03741. 
(11) Wahid, M.; Gawli, Y.; Puthusseri, D.; Kumar, A.; Shelke, M. V; Ogale, S. Nutty Carbon: Morphology Replicating Hard Carbon from Walnut Shell for $\mathrm{Na}$ Ion Battery Anode. 2017. https://doi.org/10.1021/acsomega.7b00633.

(12) Xu, S.-D.; Zhao, Y.; Liu, S.; Ren, X.; Chen, L.; Shi, W.; Wang, X.; Zhang, D. Curly Hard Carbon Derived from Pistachio Shells as High-Performance Anode Materials for Sodium-Ion Batteries. $J$. Mater. Sci. 2018, 53, 12334-12351. https://doi.org/10.1007/s10853-018-2472-4.

(13) Yu, P.; Tang, W.; Wu, F. F.; Zhang, C.; Luo, H. Y.; Liu, H.; Wang, Z. G. Recent Progress in PlantDerived Hard Carbon Anode Materials for Sodium-Ion Batteries: A Review. Rare Met. 2020, 39 (9), 1019-1033. https://doi.org/10.1007/s12598-020-01443-z.

(14) Dou, X.; Geng, C.; Buchholz, D.; Passerini, S. Research Update: Hard Carbon with Closed Pores from Pectin-Free Apple Pomace Waste for Na-Ion Batteries. APL Mater. 2018, 6 (4). https://doi.org/10.1063/1.5013132.

(15) Saurel, D.; Orayech, B.; Xiao, B.; Carriazo, D.; Li, X.; Rojo, T. From Charge Storage Mechanism to Performance: A Roadmap toward High Specific Energy Sodium-Ion Batteries through Carbon Anode Optimization. Adv. Energy Mater. 2018, 8 (17). https://doi.org/10.1002/aenm.201703268.

(16) Sommaruga, R.; Eldridge, H. M. Avocado Production: Water Footprint and Socio-Economic Implications. EuroChoices 2020. https://doi.org/10.1111/1746-692X.12289.

(17) Rincon-Patino, J.; Lasso, E.; Corrales, J. C. Estimating Avocado Sales Using Machine Learning Algorithms and Weather Data. Sustain. 2018, 10 (10). https://doi.org/10.3390/su10103498.

(18) Denvir, A.; Arima, E. Y.; González-Rodríguez, A.; Young, K. R. Ecological and Human Dimensions of Avocado Expansion in México: Towards Supply-Chain Sustainability. Ambio 2021. https://doi.org/10.1007/s13280-021-01538-6.

(19) The Packer. Top 20 Fruits and Vegetables Sold in the U.S. 
https://www.pma.com/content/articles/top-20-fruits-and-vegetables-sold-in-the-us.

(20) Araújo, R. G.; Rodriguez-Jasso, R. M.; Ruiz, H. A.; Pintado, M. M. E.; Aguilar, C. N. Avocado ByProducts: Nutritional and Functional Properties. Trends Food Sci. Technol. 2018, 80 (October 2017), 51-60. https://doi.org/10.1016/j.tifs.2018.07.027.

(21) Páramos, P. R. S.; Granjo, J. F. O.; Corazza, M. L.; Matos, H. A. Extraction of High Value Products from Avocado Waste Biomass. J. Supercrit. Fluids $2020,165$. https://doi.org/10.1016/j.supflu.2020.104988.

(22) Murugesan, K.; Tareke, K.; Gezehegn, M.; Kebede, M.; Yazie, A.; Diyana, G. Rapid Development of Activated Carbon and ZnO Nanoparticles via Green Waste Conversion Using Avocado Fruit Peel Powder and Its High Performance Efficiency in Aqueous Dye Removal Application. J. Inorg. Organomet. Polym. Mater. 2019, 29 (4), 1368-1374. https://doi.org/10.1007/s10904-019-01101-7.

(23) Leite, A. J. B.; Carmalin, S. A.; Thue, P. S.; dos Reis, G. S.; Dias, S. L. P.; Lima, E. C.; Vaghetti, J. C. P.; Pavan, F. A.; de Alencar, W. S. Activated Carbon from Avocado Seeds for the Removal of Phenolic Compounds from Aqueous Solutions. Desalin. Water Treat. 2017, 71, 168-181. https://doi.org/10.5004/dwt.2017.20540.

(24) Beda, A.; Le Meins, J. M.; Taberna, P. L.; Simon, P.; Matei Ghimbeu, C. Impact of Biomass Inorganic Impurities on Hard Carbon Properties and Performance in Na-Ion Batteries. Sustain. Mater. Technol. 2020, 26. https://doi.org/10.1016/j.susmat.2020.e00227.

(25) Chen, C.; Huang, Y.; Meng, Z.; Zhang, J.; Lu, M.; Liu, P.; Li, T. Insight into the Rapid Sodium Storage Mechanism of the Fiber-like Oxygen-Doped Hierarchical Porous Biomass Derived Hard Carbon. J. Colloid Interface Sci. 2021, 588, 657-669. https://doi.org/10.1016/j.jcis.2020.11.058.

(26) Yang, Y.; Tang, D. M.; Zhang, C.; Zhang, Y.; Liang, Q.; Chen, S.; Weng, Q.; Zhou, M.; Xue, Y.; Liu, J.; Wu, J.; Cui, Q. H.; Lian, C.; Hou, G.; Yuan, F.; Bando, Y.; Golberg, D.; Wang, X. 
"Protrusions" or "Holes" in Graphene: Which Is the Better Choice for Sodium Ion Storage? Energy Environ. Sci. 2017, 10 (4), 979-986. https://doi.org/10.1039/c7ee00329c.

(27)

Qiao, L.; Judez, X.; Rojo, T.; Armand, M.; Zhang, H. Review-Polymer Electrolytes for Sodium Batteries. J. Electrochem. Soc. 2020, 167 (7), 070534. https://doi.org/10.1149/1945-7111/ab7aa0.

(28) Zhao, X.; Ding, Y.; Xu, Q.; Yu, X.; Liu, Y.; Shen, H. Low-Temperature Growth of Hard Carbon with Graphite Crystal for Sodium-Ion Storage with High Initial Coulombic Efficiency: A General Method. Adv. Energy Mater. 2019, 9 (10). https://doi.org/10.1002/aenm.201803648.

(29)

Hu, H. Y.; Xiao, Y.; Ling, W.; Wu, Y. B.; Wang, P.; Tan, S. J.; Xu, Y. S.; Guo, Y. J.; Chen, W. P.; Tang, R. R.; Zeng, X. X.; Yin, Y. X.; Wu, X. W. A Stable Biomass-Derived Hard Carbon Anode for High-Performance Sodium-Ion Full Battery. Energy Technol. 2021, 9 (1), 1-7. https://doi.org/10.1002/ente.202000730.

(30) Zhu, X.; Jiang, X.; Liu, X.; Xiao, L.; Cao, Y. A Green Route to Synthesize Low-Cost and HighPerformance Hard Carbon as Promising Sodium-Ion Battery Anodes from Sorghum Stalk Waste. Green Energy Environ. 2017, 2 (3), 310-315. https://doi.org/10.1016/j.gee.2017.05.004.

(31) Xiao, L.; Cao, Y.; Henderson, W. A.; Sushko, M. L.; Shao, Y.; Xiao, J.; Wang, W.; Engelhard, M. H.; Nie, Z.; Liu, J. Hard Carbon Nanoparticles as High-Capacity, High-Stability Anodic Materials for Na-Ion Batteries. Nano Energy 2016, 19, 279-288. https://doi.org/10.1016/j.nanoen.2015.10.034.

(32) Qiu, S.; Xiao, L.; Sushko, M. L.; Han, K. S.; Shao, Y.; Yan, M.; Liang, X.; Mai, L.; Feng, J.; Cao, Y.; Ai, X.; Yang, H.; Liu, J. Manipulating Adsorption-Insertion Mechanisms in Nanostructured Carbon Materials for High-Efficiency Sodium Ion Storage. 2017. https://doi.org/10.1002/aenm.201700403.

(33) Hong, K.-L.; Qie, L.; Zeng, R.; Yi, Z.-Q.; Zhang, W.; Wang, D.; Yin, W.; Wu, C.; Fan, Q.-J.; Zhang, 
W.-X.; Huang, Y.-H. Biomass Derived Hard Carbon Used as a High Performance Anode Material for Sodium Ion Batteries. 2014. https://doi.org/10.1039/c4ta02068e.

Li, Y.; Yuan, Y.; Bai, Y.; Liu, Y.; Wang, Z.; Li, L.; Wu, F.; Amine, K.; Wu, C.; Lu, J. Insights into the $\mathrm{Na}+$ Storage Mechanism of Phosphorus-Functionalized Hard Carbon as Ultrahigh Capacity Anodes. Adv. Energy Mater. 2018, 8 (18). https://doi.org/10.1002/aenm.201702781.

(35)

Bobyleva, Z. V.; Drozhzhin, O. A.; Dosaev, K. A.; Kamiyama, A.; Ryazantsev, S. V.; Komaba, S.; Antipov, E. V. Unveiling Pseudocapacitive Behavior of Hard Carbon Anode Materials for SodiumIon $\quad$ Batteries. $\quad$ Electrochim. $\quad$ Acta $\quad \mathbf{2 0 2 0}, \quad 354, \quad 136647$. https://doi.org/10.1016/j.electacta.2020.136647.

(36) Zhang, Y.; Li, X.; Dong, P.; Wu, G.; Xiao, J.; Zeng, X.; Zhang, Y.; Sun, X. Honeycomb-like Hard Carbon Derived from Pine Pollen as High-Performance Anode Material for Sodium-Ion Batteries. ACS Appl. Mater. Interfaces 2018, 10 (49), 42796-42803. https://doi.org/10.1021/acsami.8b13160.

Zhang, Q.; Deng, X.; Ji, M.; Li, Y.; Shi, Z. Hard Carbon Microspheres Derived from Resorcinol Formaldehyde Resin as High-Performance Anode Materials for Sodium-Ion Battery. Ionics (Kiel). 2020, 26 (9), 4523-4532. https://doi.org/10.1007/s11581-020-03585-7.

(38) Hu, Z.; Wang, L.; Zhang, K.; Wang, J.; Cheng, F.; Tao, Z.; Chen, J. MoS2 Nanoflowers with Expanded Interlayers as High-Performance Anodes for Sodium-Ion Batteries. Angew. Chemie - Int. Ed. 2014, 53 (47), 12794-12798. https://doi.org/10.1002/anie.201407898.

(39) Wu, L.; Pei, F.; Mao, R.; Wu, F.; Wu, Y.; Qian, J.; Cao, Y.; Ai, X.; Yang, H. SiC-Sb-C Nanocomposites as High-Capacity and Cycling-Stable Anode for Sodium-Ion Batteries. Electrochim. Acta 2013, 87, 41-45. https://doi.org/10.1016/j.electacta.2012.08.103.

(40) Bai, P.; Han, X.; He, Y.; Xiong, P.; Zhao, Y.; Sun, J.; Xu, Y. Solid Electrolyte Interphase Manipulation towards Highly Stable Hard Carbon Anodes for Sodium Ion Batteries. Energy Storage 
Mater. 2020, 25 (October 2019), 324-333. https://doi.org/10.1016/j.ensm.2019.10.006.

(41) Alvin, S.; Chandra, C.; Kim, J. Controlling Intercalation Sites of Hard Carbon for Enhancing Na and K Storage Performance. Chem. Eng. J. 2021, 411 (December 2020), 128490. https://doi.org/10.1016/j.cej.2021.128490. 


\section{FOR TABLE OF CONTENTS ONLY}

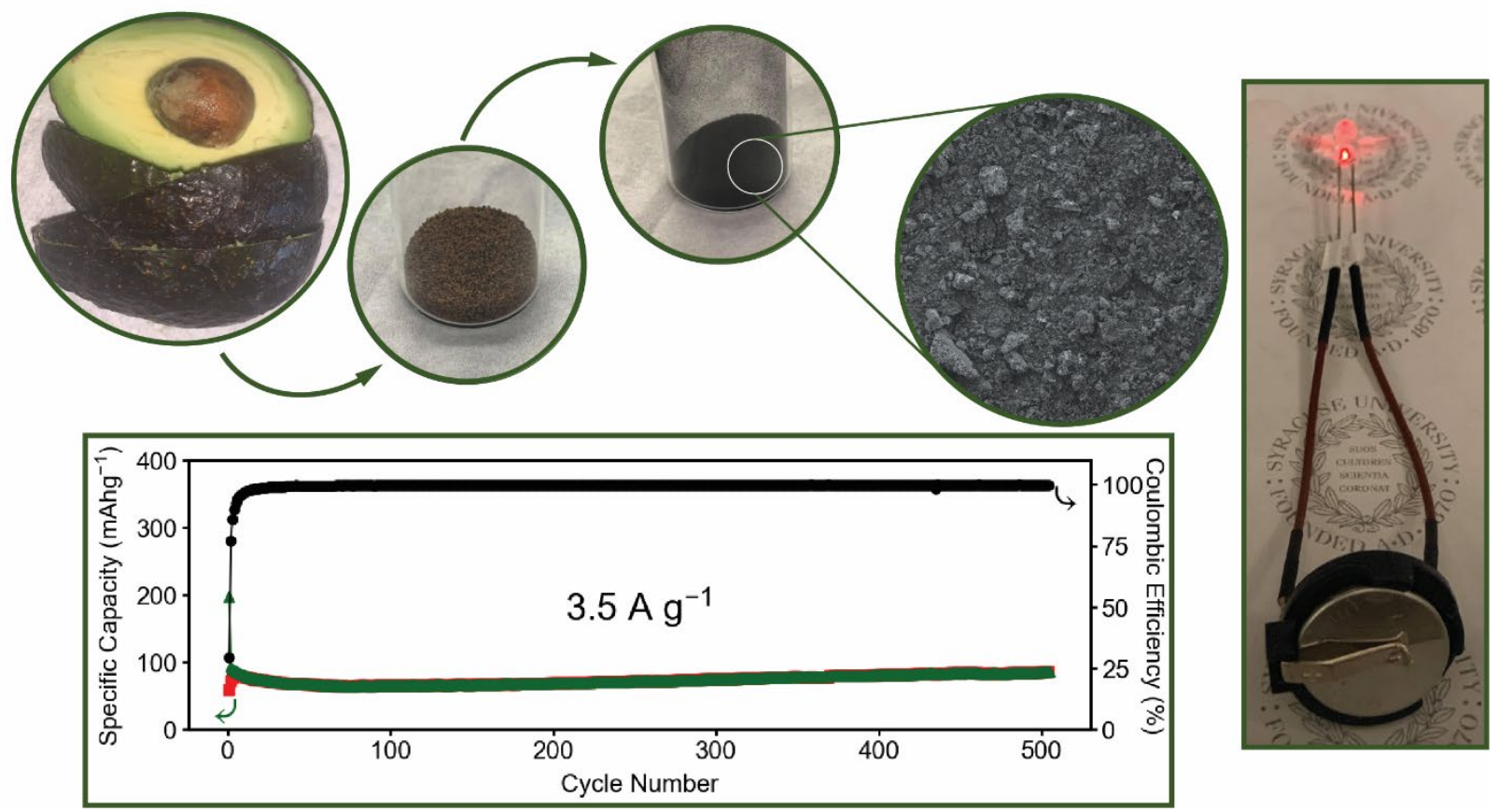

